\title{
Salinity effects on anguillicolosis in Atlantic eels: a natural tool for disease control
}

\author{
François Lefebvre $^{1,2}$, Alain J. Crivelli ${ }^{1, *}$ \\ ${ }^{1}$ Biological Station of the Tour du Valat, Le Sambuc, 13200 Arles, France \\ ${ }^{2}$ Present address: 47 rue des Trois, 86000 Poitiers, France
}

\begin{abstract}
Anguillicolosis, the disease caused by the invasive nematode Anguillicoloides crassus, is one of the many threats facing the already endangered Atlantic eel species. We conducted a systematic review of literature data linking water salinity and prevalence of the infection during the continental phase of Anguilla anguilla and A. rostrata. Overall, we showed a significant negative relationship across all sites $\left(\mathrm{r}_{\mathrm{S}}=-0.42, \mathrm{n}=77\right)$. In order to limit the effect of confounding factors (e.g. variable latitudes and parasite introduction dates), we performed a meta-analysis on the correlation coefficients calculated from data within studies (restricted period and area) and revealed a stronger negative relationship $(\bar{r}=-0.75, \mathrm{n}=13)$. Finally, using our long-term monitoring in a French Mediterranean lagoon, we documented a step decrease in both parasite prevalence and induced swimbladder pathologies in response to increased salinity values. Salinity effects manifested with an apparent threshold value around $15 \%$ and are readily appreciable in young-of-the-year eels. To date, managing around water salinity parameters remains one of the best options to control the ever-expanding infection (both in aquaculture and in the wild) and to improve the quality of future spawners en route to the Sargasso Sea.
\end{abstract}

KEY WORDS: Anguilla spp. Anguillicoloides crassus $\cdot$ Epizootic $\cdot$ Nematode $\cdot$ Parasitic invader Catadromy $\cdot$ Salt water $\cdot$ Aquaculture $\cdot$ Habitat management

\section{INTRODUCTION}

Eels of the genus Anguilla exhibit a complex amphihaline life cycle, with a reproductive phase in the ocean and a growing phase in coastal, estuarine and inland waters. Partly because of this long-run life cycle, eels are exposed to many risk factors, including oceanic changes, migration barriers, habitat loss, pollution, food depletion, etc. Moreover, most species are valuable commercial fish and additionally suffer from overfishing at all stages of their continental life (from glass eel to silver eel). Since the 1970-1980s, both scientific monitoring and fishery statistics have recorded a drastic decline in recruitment, yield and stock of eels (Dekker 2003, Casselman \& Cairns 2009). The phenomenon is worldwide, but particularly marked for the American eel Anguilla rostrata, which was ranked as a species of special concern (COSEWIC 2006), and the European eel A. anguilla, now considered 'outside safe biological limits' (ICES 2007) and red-listed as Critically Endangered (Freyhof \& Kottelat 2008).

Since the 1980-1990s, the 2 Atlantic eel species are facing a new threat. The invasive nematode Anguillicoloides (formerly Anguillicola) crassus has been expanding over the geographic range of its new hosts (Jakob et al. 2009a, Rockwell et al. 2009, Lefebvre et al. 2012). It is considered one of the most pathogenic parasites of eels, with possible negative effects on body condition, swimming capacity and survival (Kennedy 2007, Palstra et al. 2007, ICES 2009a, Haenen et al. 2010). Moreover, repeated infections during the continental life of the eel lead to profound damages of the swimbladder, which may impair the spawning 
migration to the Sargasso Sea (Palstra et al. 2007, Clevestam et al. 2011, Lefebvre et al. 2012).

It is often assumed that there is not much that can be done to hinder the parasite, except to prevent its expansion via limiting the volume of intercontinental eel trades and applying stringent sanitary controls over the translocations of live fish (Taraschewski 2006, CITES 2007, Kennedy 2007). Noteworthy, however, is that eel farms using seawater were often found free of the parasite (Kamstra 1990, Køie 1991), and eels living in brackish and coastal waters most often showed a lower infection rate than those taken in neighbouring freshwater areas (Dekker \& van Willigen 1989, Nielsen 1997, Morrison \& Secor 2003).

High salinities can create unsuitable or non-optimal eco-physiological conditions for the parasite to complete its life cycle. First, high salinity may narrow the range of available/compatible hosts (whether intermediate or paratenic), and the presence of vector hosts in the medium is of primary importance, especially in the context of parasitic colonization (Taraschewski 2006, Anderson \& Sukhdeo 2010). Second, experimental studies clearly demonstrated that high salinity concentrations adversely affect egg hatching, larval survival and infectivity of Anguillicoloides crassus (De Charleroy et al. 1989, Kirk et al. 2000a), likely via a deleterious osmotic stress operating at all the free-living stages of the parasite cycle (Scholz \& Zerbst-Boroffka 1994).

Due to the increased concern about this new parasitic threat, many epidemiological studies have been published (in almost every colonized country) that provided a large but confused picture about the true relationship between infection rates and salinity values. Indeed, punctual samplings only provide a snapshot into a dynamic host-parasite-environment system (Poulin 2007, Anderson \& Sukhdeo 2010). Water salinity, for instance, may vary on a very short time scale in response to tidal cycles (e.g. in estuaries), climatic events (e.g. flooding, drought) or anthropogenic factors (e.g. human management). Yet Anguillicoloides crassus has been observed over a wide range of salinity levels, including hyperhaline waters (e.g. Loukili \& Belghyti 2007, Rockwell et al. 2009). So far the only attempt to review the question failed to demonstrate any significant relationship between water salinity and local epidemiological parameters (based on 5 recent studies, see Neto et al. 2010).

Here we aimed to explore all available data at hand to determine whether salinity actually reduces parasite pressure by Anguillicoloides crassus. Because there are many possible confounding factors (e.g. temperature, parasite introduction date, host size), the analyses were conducted at 3 levels to sequentially eliminate or control their effects. Hence, we considered the relationships between salinity and prevalence values (1) on a broad scale, across all published studies (exhaustive data set but many confounding factors); (2) on a smaller scale within studies (meta-analysis of individual correlation coefficients); and (3) within site, by monitoring over several years the infection pressure following salinity changes. The potential uses of salinity in controlling the expanding infection (both in aquaculture and in the wild) and in improving the quality of future spawners are analyzed in regard to the eel management plans that are being implemented.

\section{MATERIALS AND METHODS}

\section{Literature search}

To ensure that we were working with high-quality data (and to avoid data redundancy), we focused solely on published articles in peer-reviewed journals, leaving out internal reports, theses and dissertations, and other 'grey' literature. Using the keywords 'anguillicol*' and 'salinity or brackish or salt"', we searched the following 3 bibliographic databases for identifying articles with both epidemiological and salinity data: Helminthological Abstracts (1973-2011), Web of Science (1981-2011) and Zoological Records (1864-2011).

We extracted infection data only when associated with a numerical measure of salinity, thus excluding a significant amount of epidemiological information available in the literature. We did so, (1) because the distinction between qualitative salinity indications such as fresh, brackish or salt waters is variable depending on the authors and their respective scientific domains, and (2) to avoid placing undue emphasis on infection data from freshwater habitats (e.g. reservoirs, ponds, lakes, rivers) for which a salinity measure was rarely reported. Also, we kept only studies in which non-null infection rates with Anguillicoloides crassus were recorded for at least one sampling site, to ensure the parasite was indeed present in the investigated area.

Applying these selection criteria, 14 out of the 39 identified articles provided actual data on the epidemiology of the infection and salinity values at the corresponding sampled site. To complement the literature search, we also used the reference lists given in the most recent and detailed studies on the epidemi- 
ology of the infection in the 2 Atlantic eel species (e.g. Jakob et al. 2009a for Anguilla anguilla, and Aieta \& Oliveira 2009 for A. rostrata). This added 12 more articles with useful paired data. Further, we searched our personal collection of literature to identify additional but non-referenced articles in the above cited sources. We found 8 more articles reporting both epidemiological and salinity data. At the end of the literature search process, we considered that we were working with a 'quasi-exhaustive' set of published data (for a detailed list of the selected studies, see the supplement at www.int-res.com/articles/ suppl/m471p193_supp.pdf).

\section{Data preparation}

When sampling of eels was repeated several times at the same place (e.g. multiple-year monitoring), we re-calculated (if needed) mean prevalence and salinity values over the studied period so that we were working with one pair of data per sampled site and per published study. For studies reporting prevalence and salinity from multiple sample sites, paired data were treated as independent points when they came from different water bodies or differed enough in habitat type (e.g. upstream-downstream samples). We considered epidemiological data from yellow eels only, because silver eels (seaward migrant stage) likely spent most of their continental phase under salinity values that were different from where they were caught. Also, we considered only data on adult and pre-adult parasites (swimbladder lumen worms), thus excluding any larval count from the computation.

Throughout, prevalence was defined as the percentage of infected individuals in a given sample of hosts (see Bush et al. 1997). Because estimates of prevalence are unreliable if the host sample size is too small (Jovani \& Tella 2006), data were only included if the number of examined eels was $\geq 15$ individuals. For comparative purpose, salinity values were consistently expressed in parts per thousand of dissolved salts (ppt or \%). When salinity indication was given in terms of conductivity $\left(\mathrm{S} \mathrm{m}^{-1}\right.$, or any derivatives), it was converted using the online tool available at www.lenntech.com/calculators/ conductivity/tds-engels.htm.

\section{Between-study relationship}

In a first step, we assessed the global correlation between prevalence and salinity values (raw data as reported in the literature) using the Spearman's rank test $\left(\mathrm{r}_{\mathrm{S}}\right.$, for comparative purposes with the later metaanalytic result).

In a second step, 2 additional variables known to influence the infection rate were considered: host size and water temperature. Total body length $\left(L_{T}\right.$, in $\mathrm{mm}$ ) was extracted from the study report (mean or median values) and used as covariate to control for its effect. Water temperature was estimated from latitude coordinates at the sampling site, considering the close relationship that links these 2 factors on a global scale (in general, the higher the latitude, the lower the water temperature, and vice versa). For comparative purpose, latitude values were consistently expressed in decimal degrees (DD system; e.g. +41.95), if needed using the online converter available at www.csgnetwork.com/gpscoordconv.html. When there were no geographic coordinates or localities explicitly given in the text, the latitude was taken at the middle of the water body using the georeferencer tool in Google Earth (version 6.0.2).

To evaluate the respective influences of latitude and salinity on prevalence value (controlling for size), a multiple regression analysis was performed. Variables were transformed whenever necessary to approximate the normality assumption for parametric analyses. The goodness of fit of the model was assessed by the coefficient of determination $\left(\mathrm{R}^{2}\right)$, which measures the proportion of explained variance, and the relative contribution of each predictor was assessed by the magnitude of the standardized regression coefficients ( $\beta$ ).

\section{Within-study relationship}

Here, we analyzed the relationship between salinity and prevalence within restricted study periods and geographical areas (to limit the effect of confounding factors, such as variable temperatures or parasite introduction dates). For a subset of studies reporting local data at multiple sampling sites, we computed individual correlation coefficients between prevalence and salinity values. Because the minimum number of paired data points required for reliable Pearson's correlation coefficient was generally not met (i.e. $n \geq 5$, see Abdel-Megeed 1984), the alternative Spearman's rank correlation was applied throughout.

The mean correlation coefficient over the subset of studies $(\bar{r})$ was computed using the meta-analytic software MIX (version 1.7). To run the program we first converted individual $r_{S}$ values into Fisher 
$z$-values, and weighted each effect size with its sampling standard error (SE), calculated as follows: $\mathrm{SE}=\mathrm{r}_{\mathrm{S}} /$ $t_{(\mathrm{n}-2)}$, where $t_{(\mathrm{n}-2)}$ is the Student's $t$ value for $\mathrm{n}-2$ degrees of freedom (Hunter \& Schmidt 2004). The decision of whether to apply a fixed-effect model (assuming only within-study variability) versus a random-effect model (allowing both within- and between-studies variability) was based upon the $Q$ statistic, which measures the heterogeneity of $r_{S}$ among the set of studies.

\section{Within-site relationship}

In the study area, the Vaccarès Lagoon $\left(65 \mathrm{~km}^{2}\right.$, French Mediterranean coast), both human and climatic factors have created important salinity variations in the past decades (see Heurteaux 1992, Poizat et al. 2004). In 1993, the mean salinity dropped in a week from $15 \%$ to $6 \%$, after a centennial flood of the Rhône River broke the dikes. It remained below $8 \%$ until the main stakeholders of the water system (i.e. fishermen and rice producers) agreed in 1998 to reach and maintain the pre-flood level at $\sim 15 \%$ o (via sluices letting in salt water from the Mediterranean Sea, and controlling the input of freshwater from the Rhône River). In recent years, salinity variations were mostly the result of climatic conditions, with a peak up to $25 \%$ in 2008 due to 2 successive dry years, and then a marked decrease following wetter seasons $(13 \%$ in 2011 ; Table 1, see also Fig. 3). In this water system, the parasite Anguillicoloides crassus was first observed in eel Anguilla anguilla in 1995, and long-term monitoring of the infection was initiated in the subsequent years (epidemiological data are partially available in Lefebvre et al. 2002a and Lefebvre \& Crivelli 2004).

At our 2 sampling sites (Capelière station, $43^{\circ} 31^{\prime} 57^{\prime \prime} \mathrm{N}, 4^{\circ} 38^{\prime} 24^{\prime \prime} \mathrm{E}$, and Impériaux station, $43^{\circ} 30^{\prime} 25^{\prime \prime} \mathrm{N}, 4^{\circ} 27^{\prime} 08^{\prime \prime} \mathrm{E}$ ), sampling was conducted monthly from 1997 to 2011 during at least 6 months of the year (April-June and September-November, periods selected to best encapsulate the annual catch information; A. J. Crivelli unpubl. data). At each sampling site, 2 fyke nets (one with a $6 \mathrm{~mm}$ mesh in the funnels and a leading net of $40 \mathrm{~m}$, the other with $0.5 \mathrm{~mm}$ mesh and a leading net of $20 \mathrm{~m}$ ) were set on
4 consecutive days per month and visited every $24 \mathrm{~h}$. However, because the catches drastically dropped in the early 2000s, no parasitological surveys were performed in 2003, and for the period 2004-2007, only young-of-the-year eels $\left(L_{\mathrm{T}}<190 \mathrm{~mm}\right)$ caught in September-November at one sampling site (Capelière) were examined. For every collected eel, we recorded $L_{\mathrm{T}}$ and the number of swimbladder lumen worms (adult and pre-adult parasites). In addition, starting from the year 2000, we recorded the swimbladder degenerative index (SDI), which evaluates the gross pathologies induced by the parasite in the swimbladder organ (see Lefebvre et al. 2002b). The SDI is computed using 3 criteria, each one coded as 0,1 or 2 (increasing degradation): opacity of the swimbladder wall, presence of pigmentation on the swimbladder wall and/or exudates in the swimbladder lumen, and thickness of the swimbladder wall.

Using this long-term data set (Table 1), we explored the effects of salinity changes on both prevalence and SDI using generalized linear models. We first performed a stepwise selection procedure to identify (in addition to body size $L_{\mathrm{T}}$ ) which of the possible salinity parameters best fit the annual change in prevalence (current year salinity, annual salinity up to the preceding 4 years, or mean salinity over the preceding years up to $\mathrm{n}-4$ years). We then per- 
formed multiple linear regressions to test the relative contribution of this best salinity parameter and eel size $\left(L_{\mathrm{T}}\right)$ in explaining the observed variation in prevalence and SDI. Further, to limit again the effect of confounding factors, we restricted our analysis to young-of-the-year eels $\left(L_{\mathrm{T}}<190 \mathrm{~mm}\right.$, caught between September and November, data available for all years 1997-2011 except 2003) and to salinity values in the immediate preceding years (current year salinity from January to September, or annual mean salinity in the preceding 2 years). We performed linear regressions to test the contribution of the best salinity parameter on the observed variance in prevalence and SDI. All dependent variables met the normality assumption (Shapiro-Wilk's test). All regression analyses were performed with the software Statistica (version 6.0).

\section{RESULTS}

\section{Between-study relationship}

A total of 77 salinity-prevalence data pairs were extracted from 33 studies ( $\mathrm{n}=71$ for Anguilla anguilla, $\mathrm{n}=6$ for $A$. rostrata). Prevalence values ranged from 0 to $85.7 \%$ (mean $\pm \mathrm{SE}=28.25 \pm 3.00$, median $=21.30$ ) and salinity values from 0 to $46.8 \%$ $($ mean $\pm \mathrm{SE}=17.02 \pm 1.54$, median $=16.50)$. In the first analysis, we found an overall significant negative correlation between prevalence and salinity values $\left(\mathrm{r}_{\mathrm{S}}=-0.42, \mathrm{p}<0.001\right.$; Fig. 1).

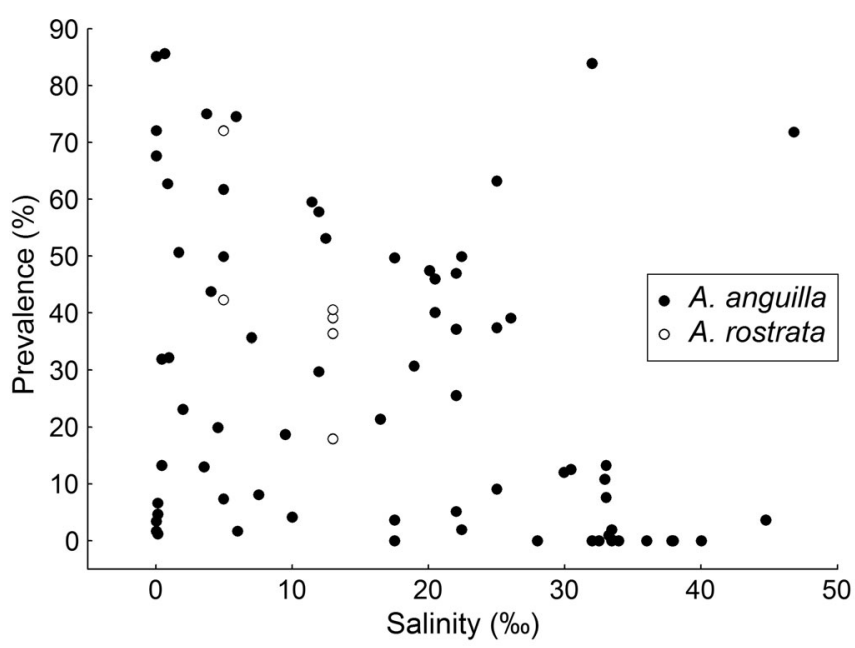

Fig. 1. Paired data points $(\mathrm{n}=77)$ between Anguillicoloides crassus prevalence in Atlantic eels Anguilla spp. and water salinity at the sampling site (raw data from literature studies, see the Supplement at www.int-res.com/articles/suppl/ m471p193_supp.pdf).
Table 2. Contributions of 3 selected predictors (eel length $\left[L_{\mathrm{T}}\right]$, salinity and latitude of the sampling sites) to the observed variance in Anguillicoloides crassus prevalence $\left(\mathrm{R}^{2}=\right.$ $\left.0.24, F_{3,68}=7.01, \mathrm{p}<0.001\right)$. Data were extracted from the literature for the 2 Atlantic eel species, Anguilla anguilla and $A$. rostrata. $\beta$ : standardized coefficient of regression (independent contribution); B: non-standardized coefficient of regression (slope)

\begin{tabular}{|lrrrr|}
\hline Model terms & $\beta$ & $\mathrm{B}$ & \multicolumn{1}{c}{$t$} & \multicolumn{1}{c|}{$\mathrm{p}$} \\
\hline Intercept & & 97.83 & 4.95 & $<0.001$ \\
Salinity & -0.45 & -0.90 & -4.01 & $<0.001$ \\
Latitude & -0.42 & -1.42 & -3.39 & $<0.01$ \\
$L_{\mathrm{T}}$ & 0.11 & 0.03 & 0.94 & 0.35 \\
\hline
\end{tabular}

Latitude values of the 77 sampling sites were all positive (no sampled sites from the Southern Hemisphere) and ranged from +34.26 to $+60.22^{\circ}$ (mean \pm $\mathrm{SE}=+46.39 \pm 0.88$, median $=+44.62$ ). Fish lengths were extracted from 72 sample reports (no size data readily available in 5 cases): $L_{\mathrm{T}}$ covered all size classes of yellow eels, ranging from 209 to $840 \mathrm{~mm}$ $($ mean $\pm \mathrm{SE}=426.58 \pm 13.61$, median $=415)$.

The multiple regression analysis revealed that the mean body size of eels had no significant effect on the observed prevalence values (Table 2). In contrast, both the latitude and salinity at the sampling site significantly influenced the infection rate. The higher the latitude the lower the prevalence $(\beta=-0.42$, $\mathrm{p}<0.01$ ) and, even more significantly, the higher the salinity the lower the prevalence $(\beta=-0.45, \mathrm{p}<$ $0.001)$. The proportion of explained variance by the model was highly significant but low $\left(\mathrm{R}^{2}=0.24\right.$, $\mathrm{p}<0.001$ ), indicating that other factors likely interact with the salinity-prevalence relationship.

\section{Within-study relationship}

Thirteen studies met the inclusion criteria (i.e. at least 3 paired prevalence-salinity values, and a minimal sample size of 15 eels to estimate prevalence), of which only one concerned Anguillicoloides crassus in the American eel Anguilla rostrata. All but one study $(92 \%)$ reported negative correlation coefficients between salinity and prevalence $\left(-1.0 \leq \mathrm{r}_{\mathrm{S}} \leq+0.87\right.$; Fig. 2), of which 10 were not statistically significant at $\mathrm{p}<0.05$. The $Q$ statistic was not significant $(Q=12.61$, $\mathrm{p}=0.40$ ), so revealing no major heterogeneity among $\mathrm{r}_{\mathrm{S}}$ values, and a fixed model was applied for running the meta-analysis. The weighted mean correlation coefficient for the 13 studies was $\bar{r}=-0.75$ (95\% CL: $\pm 0.21, z=6.91, \mathrm{p}<0.001)$. 


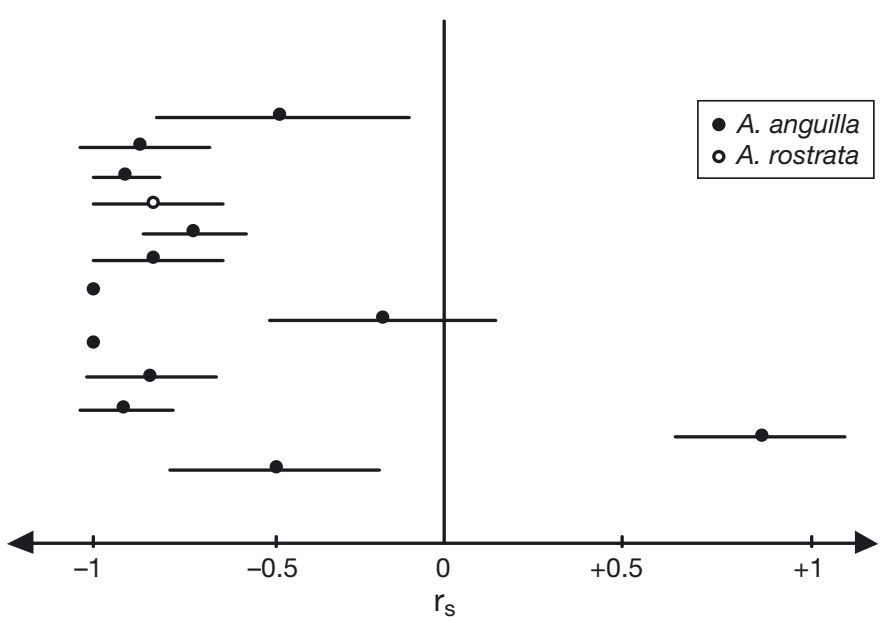

Fig. 2. Distribution of the 13 effect sizes (Spearman's rank correlation coefficients, $\mathrm{r}_{\mathrm{S}} \pm \mathrm{SE}$ ) between Anguillicoloides crassus prevalence in Atlantic eels Anguilla spp. and water salinity, within restricted study period and geographic area (data computed from multi-site studies, see the supplement)

\section{Within-site relationship}

In multiple forward regressions, entering $L_{\mathrm{T}}$ and multiple derivatives of salinity as potential predictors, the best fit was obtained with mean salinity values over the last 3 yr (Table 3 ). There were negative relationships between both prevalence and SDI values and the level of salinity experienced by fish $(\beta=-0.65, p=0.05$ and $\beta=-0.78, p=0.06$, respectively), but the models were not significant $\left(\mathrm{R}^{2}=0.33\right.$, $\mathrm{p}=0.11$ and $\mathrm{R}^{2}=0.37, \mathrm{p}=0.15$, respectively).

Looking at young-of-the-year only, we found significant negative relationships between mean salinity during the preceding year and both prevalence and

Table 3. Contributions of selected predictors (eel length $\left[L_{\mathrm{T}}\right]$ and salinity of the sampling site) to the observed variance in Anguillicoloides crassus prevalence $\left(\mathrm{R}^{2}=0.33, F_{2,11}=2.69\right.$, $\mathrm{p}=0.11$ ) and swimbladder degenerative index (SDI: $\mathrm{R}^{2}=$ 0.37, $F_{2,8}=2.39, p=0.15$ ) for European eel Anguilla anguilla at our field monitoring site (Vaccarès Lagoon, French Mediterranean coast). $\beta$ : standardized coefficient of regression (independent contribution); B: non-standardized coefficient of regression (slope)

\begin{tabular}{|lrrrr|}
\hline Model terms & \multicolumn{1}{c}{$\beta$} & $\mathrm{B}$ & \multicolumn{1}{c}{$t$} & $\mathrm{p}$ \\
\hline Prevalence & & & & \\
Intercept & & 66.78 & 4.20 & $<0.01$ \\
Salinity (3 yr) & -0.65 & -2.43 & -2.21 & 0.05 \\
$L_{\mathrm{T}}$ & 0.17 & 0.04 & 0.59 & 0.56 \\
SDI & & & & \\
Intercept & & 3.66 & 2.94 & $<0.01$ \\
Salinity (3 yr) & -0.78 & -0.21 & -2.19 & 0.06 \\
$L_{\mathrm{T}}$ & 0.48 & 0.01 & 1.33 & 0.22 \\
\hline
\end{tabular}

SDI values (prevalence: $\beta=-0.62, \mathrm{R}^{2}=0.38, F_{1,12}=$ 7.50, $\mathrm{p}=0.02$; SDI: $\beta=-0.71, \mathrm{R}^{2}=0.50, F_{1,9}=9.07, \mathrm{p}=$ 0.01). In other words, the higher the salinity level the year before young eels entered the lagoons, the smaller their infection rate and the damages in the infected organ. It is noteworthy that both prevalence and SDI values substantially dropped when salinity values rose above 15\% (i.e. 2005-2006; Fig. 3).

\section{DISCUSSION}

\section{Relationships between parasite load and water salinity}

In the first analysis, we found a clear negative correlation between salinity and Anguillicoloides crassus prevalence values across all sites $\left(\mathrm{r}_{\mathrm{S}}=-0.42\right.$, $\mathrm{p}<0.001$ ), but we also showed that infection rates are influenced by latitude $(\beta=-0.42, p<0.01)$. Thus, low prevalences are more often found associated with high latitudes. Because latitude is a reasonable proxy for mean water temperature, this tends to give support to the 'temperature limit' hypothesis, according to which the parasite's geographic expansion would stop under high latitudes (Knopf et al. 1998). However, this trend observed at a global scale does not preclude the colonization of the northernmost range of the eel hosts, as recently documented by the occurrence of $A$. crassus above $60^{\circ} \mathrm{N}$ (e.g. Jakob et al. 2009a for Anguilla anguilla in Scandinavian countries, and Aieta \& Oliveira 2009 for A. rostrata in Canada). In this global analysis, however, water salinity ranked first in explaining the observed variation in prevalence values $(\beta=-0.45, \mathrm{p}<0.001)$.

In the second approach, to further limit the effect of confounding factors (e.g. water temperature, parasite introduction date), we looked at the close relationship between prevalence and salinity within restricted areas, over the same period, and then computed a mean estimate of association (meta-analysis of within-site correlation coefficients). We obtained an even stronger negative association between the 2 variables $(\bar{r}=-0.75)$. Clearly, high salinities limit, if not preclude, high infection rates by Anguillicoloides crassus.

In the third approach, using our long-term monitoring in the Vaccarès Lagoon (French Mediterranean coast), we documented a tied association between water salinity and prevalence values. Further, we showed that the mean salinity over the previous $3 \mathrm{yr}$ is the best predictor of the annual variation in infection rates. Thus, there appears to be a lag time 

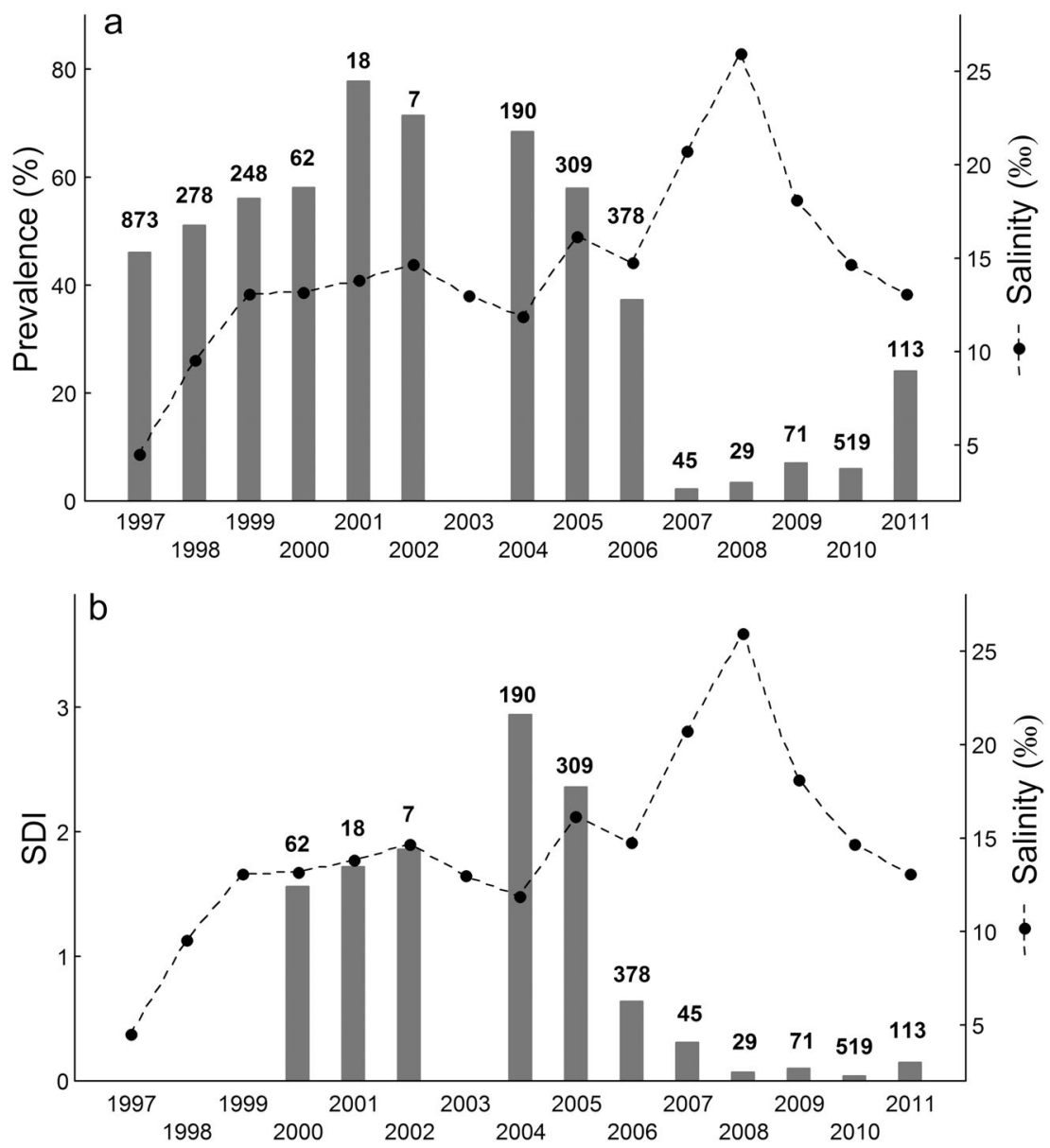

Fig. 3. Time series of (a) Anguillicoloides crassus infection rates (prevalence) and (b) swimbladder degenerative index (SDI) in relation to water salinity (dashed lines) in young-of-the-year Anguilla anguilla. In the studied water system (Vaccarès Lagoon, French Mediterranean coast), the parasite was first observed in 1995. Annual sample sizes are given above bars

Here, the 1-yr delay could correspond to the necessary lag time for the parasite to complete its life cycle and also to possible salinity effects on the first (crustacean) infection step.

From the present results and previous laboratory experiments, it appears that there is a threshold salinity value (around 15\%) above which Anguillicoloides crassus development and/or life cycle completion is severely impaired. To quote Scholz \& Zerbst-Boroffka (1994, p. 103) 'A. crassus depends almost completely on the osmotic and ionic regulation carried out by its host, for the parasite shows only very limited abilities of its own.' Køie (1991), for instance, failed to infect various crustaceans (e.g. Corophium volutator, Gammarus sp., Idothea sp.) in a salinity medium of $15 \%$, and Kennedy \& Fitch (1990) obtained a limited success in infecting only one specimen of the brackish water amphipod Eurytemora affinis they exposed to infective larvae.

\section{Potential control and management measures}

It is tempting to take advantage of the eco-physiological needs of both the host and the parasite to control over the infection. On the one hand, Anguillicoloides crassus appears to be primar-

between a change in water salinity and the epidemiological response. This may be due to a resilience phenomenon or 'stock effect', because it was shown that the parasite's eggs, or its larval stages encysted in paratenic hosts or in the eel hosts, can survive for many months (eventually years) under adverse environmental conditions (e.g. chemotherapeutic and hyperbaric treatments; see Fontaine et al. 1990 or Kamstra 1990), including 100\% seawater (Kennedy \& Fitch 1990, Kirk et al. 2000a,b). Similarly, delays are also observed in the SDI (pathological) response, which would indicate that swimbladder damages are persistent, and that a global improvement of the eel quality only occurs after the disappearance of the most severely affected individuals. Accordingly, the epidemiological response in young-of-the-year eels (for both prevalence and SDI) better matched the salinity value during the immediate preceding year. ily a freshwater parasite, as judged by its optimum development in low salinity conditions (De Charleroy et al. 1989, Nagasawa et al. 1994). On the other hand, anguillids, although commonly called 'freshwater eels', are clearly of marine origin and seem to demonstrate only facultative catadromy (Fontaine 1996, Tsukamoto et al. 1998, Aoyama 2009).

Therefore, one can consider using salinity as a natural tool for disease control. This measure has already received the support of many ichthyoparasitologists and eel specialists (Sauvaget et al. 2003, Loukili \& Belghyti 2007, ICES 2009a,b, Jakob et al. 2009b). However, to achieve general agreement and enter into common use, it should meet the interests of most, if not all, stakeholders of a water system (e.g. rice producers and fishermen), and ultimately ensure the sustainable use of the stock. We believe that favouring brackish water habitats would con- 
tribute to achieve these objectives. First, favouring higher salinity medium would also reduce the infection rate by this and other pathogenic eel parasites (e.g. the also invasive monogeneans Pseudodactylogyrus bini and P. anguillae; Køie 1988, 1991, Kennedy et al. 1997, Jakob et al. 2009b). For instance, in the lagoon Ichkeul (North Tunisia), a human-driven salinity increase, together with severe droughts at the end of the 1980s, led to a reduced infection pressure by freshwater parasites on the local fish communities (Aouij \& Zaouali 1994). Second, favouring brackish environments would also benefit the growth, condition and overall production in eel biomass (for Anguilla anguilla, see Acou et al. 2003, Daverat \& Tomás 2006; for A. rostrata, see Lamson et al. 2009, Fenske et al. 2010). Ecological reasons for higher productivity in brackish waters are discussed extensively in Gross et al. (1988) and Morrison \& Secor (2003), but may ultimately rely on the lower resting metabolism rate from living in near-isosmotic conditions (natural osmolality of eel at $\sim 290-300$ mOsm $\mathrm{kg}^{-1}$ ), which corresponds to $\sim 10 \%$ salt concentrations (Schmidt-Nielsen 1997, Boeuf \& Payan 2001, Rankin 2009).

Alternatively, favouring freshwater environments and allowing harvest in brackish waters may be a defensible management policy (Morrison \& Secor 2003, Lamson et al. 2009). The lower productivity and the late age of maturity of eels in freshwater indeed suggest that fisheries may have a larger impact in these habitats. Promoting the consumption and culture of larger specimens was indeed among the key recommendations for saving the eel resource (Ringuet et al. 2002). Additionally, protecting freshwater habitats would also favour the production of a female-biased sex ratio (Fenske et al. 2010), and females are likely more important from a reproductive output perspective.

However, one can reasonably argue that the priority target might be to improve both the quantity and the quality of future genitors before all else, and one can expect a better escapement rate from coastal waters (Aarestrup et al. 2009, Jakob et al. 2009b), especially because of increasing concerns about the effective contribution of inland freshwater eels to the spawning stocks (Tsukamoto et al. 1998, Limburg et al. 2003, Westin 2003). In accordance with the Intercontinental Study Group of Anguillid Eels in Saline Waters (ICES 2009b), we believe that well-managed coastal lagoons and estuaries, because of their high productivity, short residence time and low parasitic burdens of their eels, may play an active role in the escapement of high quality genitors, and so more rapidly ensure a safe recovery of both the European and American eel stocks. To identify and protect 'areas producing high quality spawners' was rightly one of the recurrent recommendations of the EIFAC/ ICES Working Group on Eels that lead to the adoption of the European Eel Recovery Plan (EC 2007). We thus acknowledge the recent decisions of some EU countries to classify the lower part of estuaries and coastal lagoons as protected areas, free of fishing activities, and would recommend its broader application.

\section{CONCLUSIONS}

Water salinity may help release the parasite pressure imposed by the global invader Anguillicoloides crassus and so may be envisaged as a natural tool for disease control. In aquaculture, one can use salts more extensively for disinfection of parasitized eels, meanwhile improving the growth rate of the cultured fish. In the wild, preserving coastal and estuarine saline waters may help curing or at least reducing the parasite load of freshwater-grown silver eels, while enhancing the overall quality and the chance of resident eels reaching the Sargasso Sea.

Acknowledgements. We are grateful to G. Fazio and D. Secor for valuable comments and suggestions on earlier versions of the manuscript. We thank J.-M. Caraguel and B. Mounaix (Fish Pass Society) for helping with the parasite examination of young eels for some years. The Fondation MAVA, the NGO Migrateurs-Rhône-Méditerranée, the Agence de l'Eau, the Fédération Nationale de la Pêche en France, the PACA and LR régions, and the Conseil Général des Bouches-du-Rhône supported this study financially.

\section{LITERATURE CITED}

Aarestrup K, Okland F, Hansen MM, Righton D and others (2009) Oceanic spawning migration of the European eel (Anguilla anguilla). Science 325:1660

Abdel-Megeed SM (1984) Accuracy of correlation coefficient with limited number of points. J Exp Educ 52: 188-191

Acou A, Lefebvre F, Contournet P, Poizat G, Panfili J, Crivelli AJ (2003) Silvering of female eels (Anguilla anguilla) in two sub-populations of the Rhône delta. Bull Fr Peche Piscic 368:55-68

Aieta AE, Oliveira K (2009) Distribution, prevalence, and intensity of the swim bladder parasite Anguillicola crassus in New England and eastern Canada. Dis Aquat Org 84:229-235

Anderson TK, Sukhdeo MVK (2010) Abiotic versus biotic hierarchies in the assembly of parasite populations. Parasitology 137:743-754

Aouij S, Zaouali J (1994) Impact de la diminution des apports d'eau douce sur l'ectoparasitofaune des poissons 
de la lagune d'Ichkeul (Tunisie). Mar Life 4:47-54

Aoyama J (2009) Life history and evolution of migration in catadromous eels (genus Anguilla). Aqua-Biosci Monogr 2:1-42

$>$ Boeuf G, Payan P (2001) How should salinity influence fish growth? Comp Biochem Physiol C Toxicol Pharmacol 130:411-423

- Bush AO, Lafferty KD, Lotz JM, Shostak AW (1997) Parasitology meets ecology on its own terms: Margolis et al. revisited. J Parasitol 83:575-583

Casselman JM, Cairns DK (eds) (2009) Eels at the edge: science, status, and conservation concerns. Am Fish Soc Symp 58. American Fisheries Society, Bethesda, MD

CITES (2007) Convention on International Trade in Endangered Species of Wild Fauna and Flora, CoP14. WWF, The Hague

Clevestam PD, Ogonowski M, Sjöberg NB, Wickström H (2011) Too short to spawn? Implications of small body size and swimming distance on successful migration and maturation of the European eel Anguilla anguilla. J Fish Biol 78:1073-1089

COSEWIC (2006) Assessment and status report on the American eel Anguilla rostrata in Canada. Committee on the Status of Endangered Wildlife in Canada, Ottawa

$>$ Daverat F, Tomás J (2006) Tactics and demographic attributes in the European eel Anguilla anguilla in the Gironde watershed, SW France. Mar Ecol Prog Ser 307: 247-257

De Charleroy D, Thomas K, Belpaire C, Ollevier F (1989) The viability of the free living larvae of Anguillicola crassus. J Appl Ichthyol 5:154-156

Dekker W (2003) Worldwide decline of eel resources necessitates immediate action. Fisheries 28:28-30

- Dekker W, van Willigen J (1989) Short note on the distribution and abundance of Anguillicola in The Netherlands. J Appl Ichthyol 5:46-47

EC (2007) Council Regulation (EC) No 1100/2007 establishing measures for the recovery of the stock of European eel. Off J Eur Union L 50:17-23

Fenske KH, Secor DH, Wilberg MJ (2010) Demographics and parasitism of American eels in the Chesapeake Bay, USA. Trans Am Fish Soc 139:1699-1710

Fontaine YA (1996) Evolutionary scenarios leading to ecological transitions: an example using the life cycle of European eel. Bull Soc Zool Fr 121:213-222

Fontaine YA, Le Belle N, Lopez E, Querat B and others (1990) Infestation de populations françaises d'anguilles (Anguilla anguilla L.) par des nématodes (Anguillicola crassus): essais thérapeutiques, évaluation de risques potentiels liés à l'écophysiologie de l'hôte. Ann Parasitol Hum Comp 65:64-68

Freyhof J, Kottelat M (2008) Anguilla anguilla. In: IUCN Red List of threatened species. IUCN, Gland. Available at www.iucnredlist.org (accessed 28 Nov 2012)

- Gross MR, Coleman RM, McDowall RM (1988) Aquatic productivity and the evolution of diadromous fish migration. Science 239:1291-1293

> Haenen OLM, Lehmann J, Engelsma MY, Stürenberg FJ, Roozenburg I, Kerkhoff S, Klein Breteler J (2010) The health status of European silver eels, Anguilla anguilla, in the Dutch River Rhine Watershed and Lake IJsselmeer. Aquaculture 309:15-24

> Heurteaux P (1992) Modifications du régime hydrique et salin des étangs du système de Vaccarès (Camargue, France) liées aux perturbations anthropiques des cinquante dernières années. Int J Limnol 28:157-174

Hunter JE, Schmidt FL (2004) Methods of meta-analysis: correcting error and bias in research findings. Sage Publications, Thousand Oaks, CA

ICES (2007) Report of the 2007 session of the joint EIFAC/ ICES Working Group on Eels. ICES CM 2007/ACFM:23

ICES (2009a) Report of the 2009 session of the joint EIFAC/ ICES Working Group on Eels. ICES CM 2009/ACOM:15

ICES (2009b) Report of the Study Group on Anguillid Eels in Saline Waters (SGAESAW). ICES CM 2009/DFC:06

Jakob E, Walter T, Hanel R (2009a) A checklist of the protozoan and metazoan parasites of European eel (Anguilla anguilla): checklist of Anguilla anguilla parasites. J Appl Ichthyol, doi:10.1111/j.1439-0426.2009.01345.x

Jakob E, Hanel R, Klimpel S, Zumholz K (2009b) Salinity dependence of parasite infestation in the European eel Anguilla anguilla in northern Germany. ICES J Mar Sci 66:358-366

Jovani R, Tella JL (2006) Parasite prevalence and sample size: misconceptions and solutions. Trends Parasitol 22: $214-218$

- Kamstra A (1990) Anguillicola in Dutch eelfarms; current state. Int Rev Gesamten Hydrobiol 75:867-874

Kennedy CR (2007) The pathogenic helminth parasites of eels. J Fish Dis 30:319-334

Kennedy CR, Fitch DJ (1990) Colonization, larval survival and epidemiology of the nematode Anguillicola crassus, parasitic in the eel, Anguilla anguilla, in Britain. J Fish Biol 36:117-131

Kennedy CR, Di Cave D, Berrilli F, Orecchia P (1997) Composition and structure of helminth communities in eels Anguilla anguilla from Italian coastal lagoons. J Helminthol 71:35-40

Kirk RS, Kennedy CR, Lewis JW (2000a) Effect of salinity on hatching, survival and infectivity of Anguillicola crassus (Nematoda: Dracunculoidea) larvae. Dis Aquat Org 40: 211-218

Kirk RS, Lewis JW, Kennedy CR (2000b) Survival and transmission of Anguillicola crassus Kuwahara, Niimi \& Itagaki, 1974 (Nematoda) in seawater eels. Parasitology 120:289-295

- Knopf K, Würtz J, Sures B, Taraschewski H (1998) Impact of low water temperature on the development of Anguillicola crassus in the final host Anguilla anguilla. Dis Aquat Org 33:143-149

Køie M (1988) Parasites in European eel Anguilla anguilla (L.) from Danish freshwater, brackish and marine localities. Ophelia 29:93-118

Køie M (1991) Swimbladder nematodes (Anguillicola spp.) and gill monogeneans (Pseudodactylogyrus spp.) parasitic on the European eel (Anguilla anguilla). ICES J Mar Sci 47:391-398

Lamson HM, Cairns DK, Shiao JC, Iizuka Y, Tzeng WN (2009) American eel, Anguilla rostrata, growth in fresh and salt water: implications for conservation and aquaculture. Fish Manag Ecol 16:306-314

Lefebvre FS, Crivelli AJ (2004) Anguillicolosis: dynamics of the infection over two decades. Dis Aquat Org 62: $227-232$

> Lefebvre F, Contournet P, Priour F, Soulas O, Crivelli AJ (2002a) Spatial and temporal variation in Anguillicola crassus counts: results of a 4 year survey of eels in Mediterranean lagoons. Dis Aquat Org 50:181-188

Lefebvre F, Contournet P, Crivelli AJ (2002b) The health state of the eel swimbladder as a measure of parasite 
pressure by Anguillicola crassus. Parasitology 124: 457-463

Lefebvre F, Fazio G, Crivelli AJ (2012) Anguillicoloides crassus. In: Woo PTK, Buchmann K (eds) Fish parasites: pathobiology and protection. CABI, Wallingford, p 320-336

Limburg KE, Wickström H, Svedäng H, Elfman M, Kristiansson P (2003) Do stocked freshwater eels migrate? Evidence from the Baltic suggests 'yes'. Am Fish Soc Symp 33:275-284

Loukili A, Belghyti D (2007) The dynamics of the nematode Anguillicola crassus, Kuvahara 1974 in eel Anguilla anguilla (L. 1758) in the Sebou estuary (Morocco). Parasitol Res 100:683-686

Morrison WE, Secor DH (2003) Demographic attributes of yellow-phase American eels (Anguilla rostrata) in the Hudson River estuary. Can J Fish Aquat Sci 60:1487-1501

Nagasawa K, Kim YG, Hirose H (1994) Anguillicola crassus and A. globiceps (Nematoda: Dracunculoidea) parasitic in the swimbladder of eels (Anguilla japonica and A. anguilla) in East Asia: a review. Folia Parasitol 41:127-137

Neto AF, Costa JL, Costa MJ, Domingos I (2010) Epidemiology and pathology of Anguillicoloides crassus in European eel Anguilla anguilla from the Tagus estuary (Portugal). Dis Aquat Org 88:225-233

Nielsen ME (1997) Infection status of the swimbladder worm, Anguillicola crassus in silver stage European eel, Anguilla anguilla, from three different habitats in Danish waters. J Appl Ichthyol 13:195-196

Palstra AP, Heppener DFM, van Ginneken VJT, Székely C, van den Thillart GEEJM (2007) Swimming performance of silver eels is severely impaired by the swim-bladder parasite Anguillicola crassus. J Exp Mar Biol Ecol 352: $244-256$

Editorial responsibility: Jana Davis, Annapolis, Maryland, USA
Poizat G, Rosecchi E, Chauvelon P, Contournet P, Crivelli AJ (2004) Long-term fish and macro-crustacean community variation in a Mediterranean lagoon. Estuar Coast Shelf Sci 59:615-624

Poulin R (2007) Evolutionary ecology of parasites. Princeton University Press, Princeton, NJ

Rankin JC (2009) Acclimation to seawater in the European eel Anguilla anguilla: effects of silvering. In: van den Thillart G, Dufour S, Rankin JC (eds) Spawning migration of the European eel, Fish and Fisheries Series, Vol 30. Springer, London, p 129-145

Ringuet S, Muto F, Raymakers C (2002) Eels: their harvest and trade in Europe and Asia. Traffic Bull 19:1-27

Rockwell LS, Jones KMM, Cone DK (2009) First record of Anguillicoloides crassus (Nematoda) in American eels (Anguilla rostrata) in Canadian estuaries, Cape Breton, Nova Scotia. J Parasitol 95:483-486

> Sauvaget B, Fatin D, Briand C (2003) Contamination par Anguillicola crassus de cinq populations d'anguilles (Anguilla anguilla) du littoral de Bretagne sud (France). Bull Fr Peche Piscic 368:21-26

Schmidt-Nielsen K (1997) Animal physiology: adaptation and environment. Cambridge University Press, Cambridge

Scholz F, Zerbst-Boroffka I (1994) Osmo- und Ionenregulation des Aalparasiten Anguillicola crassus (Nematoda) und seines Wirtes (Anguilla anguilla). Zool Beitr 35:103-117

- Taraschewski H (2006) Hosts and parasites as aliens. J Helminthol 80:99-128

> Tsukamoto T, Akai I, Tesch WV (1998) Do all freshwater eels migrate? Nature 396:635-636

> Westin L (2003) Migration failure in stocked eels Anguilla anguilla. Mar Ecol Prog Ser 254:307-311

Submitted: December 13, 2011; Accepted: September 5, 2012 Proofs received from author(s): November 29, 2012 